\title{
Comparison of clinical examination with orbital MRI evaluation in patients with thyroid orbitopathy - do we need imaging and when?
}

\author{
Aleksandra Król", Jolanta Krajewska, Barbara Michalik, Ewa Paliczka-Cieślik, Michał Kalemba, \\ Beata Jurecka-Lubieniecka, Kornelia Hasse-Lazar, Sylwia Szpak-Ulczok, Łukasz Zarudzki, Barbara Jarząb
}

From 4th Congress of the Polish Thyroid Association 2013

Lodz, Poland. 11-13 April 2013

\section{Introduction}

The frequency of Graves' orbitopathy (GO) in patients with Graves' disease (GD) depends on the method of assessment. Diagnosis based on clinical symptoms is made in about $30-50 \%$ patients, more often (70\%) after ophtalmological examination with evaluation of intraocular pressure, whereas MRI reveals GO in up to $90 \%$. Proper identification of active phase of the disease is crucial.

\section{Aim of the study}

The aim of the study was to assess the concordance between clinical examination performed by endocrinologist and MRI GO diagnosis, especially to evaluate the sensitivity of both methods in identification of active phase of the disease.

\section{Material and methods}

MRI of the orbits was performed in 85 hyperthyroid GD patients qualified to $131 \mathrm{I}$ therapy. The clinical GO evaluation based on CAS and NOSPECS scores was done in all subjects, however no information concerning MRI result was provided to the physician.

\section{Results}

Radiological signs of GO were present in $78 / 85$ patients (92\%). Active phase was diagnosed in $20 / 85$ subjects, among them in $16 / 20$ on the basis of clinical evaluation and in $15 / 20$ by MRI. Concordant diagnosis was made in 11 cases, whereas in the remaining 9 subjects active phase of GO was recognized by clinical (5 pts) or radiological (4 pts) features only. 7 patients with no changes in

Department of Nuclear Medicine and Endocrine Oncology, Maria

Sklodowska Curie Memorial Cancer Centre and Institute of Oncology, Gliwice Branch, Gliwice, Poland
MRI were also negative in clinical examination - $100 \%$ accurate results. In 63 patients inactive/chronic GO was described in MRI, whereas in clinical examination active disease was stated in 5/63 cases, mild GO in 19/63 and no symptoms of GO in 39/63.

\section{Conclusions}

Clinical evaluation based on CAS score shows high sensitivity in detecting active GO. MRI is recommended in doubtful cases.

Published: 5 April 2013

doi:10.1186/1756-6614-6-S2-A34

Cite this article as: Król et al:: Comparison of clinical examination with orbital MRI evaluation in patients with thyroid orbitopathy - do we need imaging and when? Thyroid Research 2013 6(Suppl 2):A34.

Submit your next manuscript to BioMed Central and take full advantage of:

- Convenient online submission

- Thorough peer review

- No space constraints or color figure charges

- Immediate publication on acceptance

- Inclusion in PubMed, CAS, Scopus and Google Scholar

- Research which is freely available for redistribution

Submit your manuscript at www.biomedcentral.com/submit
() Biomed Central

\section{() Biomed Central}

